OPEN ACCESS

Edited by:

Manuel D. Gahete,

Maimonides Biomedical Research Institute of Cordoba (IMIBIC), Spain

Reviewed by:

Marta Korbonits,

Queen Mary University of London, United Kingdom

Sabrina Chiloiro,

Catholic University of the Sacred

Heart, Italy

*Correspondence:

Manel Puig-Domingo

mpuigd@igtp.cat

Mireia Jordà

mjorda@igtp.cat

${ }^{+}$These authors have contributed equally to this work and share senior authorship

Specialty section: This article was submitted to Pituitary Endocrinology, a section of the journal

Frontiers in Endocrinology

Received: 25 December 2020 Accepted: 22 February 2021

Published: 15 March 2021

Citation:

Gil J, Jordà M, Soldevila B and Puig-Domingo M (2021) Epithelial-

Mesenchymal Transition in the

Resistance to Somatostatin

Receptor Ligands in Acromegaly.

Front. Endocrinol. 12:646210.

doi: 10.3389/fendo.2021.646210

\section{Epithelial-Mesenchymal Transition in the Resistance to Somatostatin Receptor Ligands in Acromegaly}

\author{
Joan Gil ${ }^{1}$, Mireia Jordà ${ }^{1 * t}$, Berta Soldevila ${ }^{2}$ and Manel Puig-Domingo ${ }^{1,2,3 * t}$ \\ ${ }^{1}$ Endocrine Tumours Lab, Program of Predictive and Personalized Medicine of Cancer (PMPPC), Germans Trias i Pujol \\ Research Institute (IGTP), Badalona, Spain, ${ }^{2}$ Department of Endocrinology and Nutrition, Germans Trias i Pujol University \\ Hospital, Badalona, Spain, ${ }^{3}$ Department of Medicine, Autonomous University of Barcelona, Bellaterra, Spain
}

Epithelial-mesenchymal transition (EMT) is a dynamic process by which epithelial cells loss their phenotype and acquire mesenchymal traits, including increased migratory and invasive capacities. EMT is involved in physiological processes, such as embryogenesis and wound healing, and in pathological processes such as cancer, playing a pivotal role in tumor progression and metastasis. Pituitary tumors, although typically benign, can be locally invasive. Different studies have shown the association of EMT with increased tumor size and invasion in pituitary tumors, and in particular with a poor response to Somatostatin Receptor Ligands (SRLs) treatment in GH-producing pituitary tumors, the main cause of acromegaly. This review will summarize the current knowledge regarding EMT and SRLs resistance in acromegaly and, based on this relation, will suggest new biomarkers and possible therapies to SRLs resistant tumors.

\section{Keywords: epithelial-menchymal transition, somatostatin analogs, pituitary, E-cadherin, somatotroph adenoma,} growth hormone, PitNETs, endocrine tumors

\section{INTRODUCTION}

Epithelial-mesenchymal transition (EMT) is a dynamic process that reorganizes the cell from an epithelial to a mesenchymal phenotype leading to functional changes in cell invasion and migration capacities (1). This process is triggered by microenvironment signals that cells receive which produce changes in gene expression and post-translational regulation mechanisms leading to the loss of epithelial characteristics (cell polarity, stable epithelial cell-cell junctions and interactions with extracellular matrix) and the acquisition of mesenchymal features (fibroblast-like morphology and increased migratory and invasive properties). Although it has been considered as a binary process for many years, EMT has been recently shown to occur through distinct transition cellular states that are driven by a network of transcription factors (EMT-TFs) $(2,3)$. SNAI1-2, TWIST, and ZEB protein families have been the most extensively studied EMT-TFs as they regulate the classical EMT focused on the repression of E-cadherin, the prototypic adhesion molecule; however, the list of EMT-TFs has largely grown in the last years (4).

EMT was first described in embryonic development as a process that enables the correct morphogenetic events during migration of epithelial cells from the original position to their ultimate destination. However, EMT also occurs in pathological situations such as cancer $(2,5)$. 
During the progression of solid malignancies from benign tumors to locally invading tumors, and finally to metastatic neoplasms, EMT plays a key role. However, it seems that cancer-associated EMT is only activated partially and transiently, in contrast to developmental EMT (3). This attribute and the fact that EMT programs have been associated with other cellular programs such as cell survival, stemness and resistance to drugs (4), makes EMT difficult to study by only analyzing the expression of EMT-TF network.

Recent studies suggest the involvement of EMT in first generation Somatostatin Receptor Ligands (SRLs) resistance in GH-producing pituitary tumors (6-9). Here we review the role of EMT in pituitary adenomas and discuss the relationship between EMT and SRLs resistance in GH-producing pituitary tumors as well as offer new potential biomarkers and therapeutic options.

\section{METHODS}

We performed a systematic review with the aim of summarizing the current knowledge of EMT in GH-secreting adenomas with a special focus on SRLs resistance. We performed a search in MEDLINE database using its PubMed tool of the literature available until January 2021. We searched for the terms: "Epithelial-mesenchymal transition" OR "EMT" AND "Acromegaly" OR "Pituitary adenoma" OR "Pituitary tumor" AND/OR "Somatostatin" OR "Somatostatin receptor ligands" OR "Somatostatin analogs".

\section{EPITHELIAL-MESENCHYMAL TRANSITION IN PITUITARY TUMORS}

It is well known the importance of the expression of determined transcription factors during pituitary organogenesis to give the final identity to every different hormone-secreting cell type (10), and EMT plays an important role in this embryogenic process (11). The PROP1 transcription factor, that is vital for the ontogenesis of somatotroph cells, was discovered to promote EMT during pituitary stem cell differentiation, making EMT an important step to obtain fully-functional differentiated pituitary cells $(12,13)$. These results have been validated by single-cell transcriptomic profiling of the different developmental lineages in human pituitary (14).

EMT is not only linked to pituitary through development, as E-cadherin has been related to hormone secretion in mature cells. E-cadherin reduces prolactin protein content through affecting trafficking of secretory granules (15). Furthermore, it has been also associated with follicle-stimulating hormone (FSH) content and subcellular localization in non-functioning pituitary tumors (16).

EMT also plays an important role in the aggressive biologic behavior of pituitary tumors. Pituitary tumors are the second most common primary brain tumors with invasive properties. The loss of E-cadherin, which is a key characteristic of EMT associated with poor prognosis and high grade tumors in almost all malignancies derived from epithelial cells, has also been reported in pituitary tumors. E-cadherin, a calcium-dependent cell to cell adhesion transmembrane protein, is part of a cell adhesion complex where it is associated with other proteins $(\alpha-$, $\beta-, \gamma-$ and p120-catenins) through an intracellular domain (17). Interestingly, E-cadherin can act as direct transcriptional regulator by nuclear translocation (18). In pituitary tumors, the loss of E-cadherin, specifically the loss of cytoplasmic Ecadherin, is frequently found concurrently with its detection in the nucleus (19). Importantly, nuclear staining E-cadherin is associated with tumor invasion, suggesting that cleavage of the extracellular domain of E-cadherin and nuclear translocation may participate in local invasion in pituitary tumors. Similarly, E-cadherin among other adhesion molecules was related to invasiveness and proliferative status of prolactinomas $(20,21)$. Other classical EMT markers, such as N-cadherin, SNAI1, SNAI2 and TWIST $(21,22)$ or $\beta$-catenin $(23)$ have also been associated with a worse clinical course in pituitary tumors, especially indicating an invasive phenotype, although there is some controversy regarding this subject in acromegaly $(21,24)$.

Furthermore, different other non-classical molecules related to EMT have been characterized as part of the mechanisms allowing invasiveness in pituitary tumors, such as ADAM12 (a disintegrin and metalloprotease 12), which has been postulated as an EMT inducer in these tumors (25). ADAM12 overexpression is associated with pituitary tumor invasiveness, while its silencing prevents such biological behavior. Mechanistically, ADAM12 silencing impairs ectodomain shedding of epidermal growth factor receptor (EGFR) ligands and attenuated the EGFR/ERK signaling pathway. Inhibition of EGFR signaling resulted in EMT suppression similar to repression of ADAM12. Also, a recent study by Falch at al (26). in non-functioning gonadotroph tumors reported that those tumors harboring invasive and rapid growing characteristics showed overexpression of genes involved in EMT, in particular SPAG9, SKIL, MTDH, HOOK1, CNOT6L and PRKACB.

Surprisingly, pituitary tumor transforming gene 1 (PTTG1) has been related to EMT in non-functioning pituitary adenomas (27), just the opposite role of PTTG2 (28). Other authors suggested that the mechanism triggering the EMT in pituitary tumors is linked to the expression of S100A9, a member of the S100 family of EF-hand motif $\mathrm{Ca}^{2+}$-binding proteins, mediated by activation of AKT1 (29). In addition, it has been showed that the transcriptoma of USP8 wild-type corticotropinomas, characterized by increased invasiveness, was enriched in EMT signature (30).

In another study in GH-secreting adenomas, cyclin B1 (CCNB1) knock-down was found to decrease the mesenchymal marker $\mathrm{N}$-cadherin and increase the epithelial markers $\mathrm{E}$ cadherin and p120-catenin. Thus, inactivation of cyclin B1 results in a decreased proliferation and EMT, and an increased apoptosis (31). A similar approach was used in a different study where the expression of SMAD4 was found to regulate EMT in somatotropinomas. SMAD4 was associated with invasion, increased levels of vimentin and $\mathrm{N}$-cadherin and, decreased E-cadherin (32). 
Other genes have been related to the suppression of EMT and, therefore, invasion. It is the case of collagen type VI alpha 6 (COL6A6) that inhibits cell proliferation, migration, invasion, and epithelial-mesenchymal transition (EMT) through the binding of $P 4 H A 3$ resulting in PI3K-Akt axis inhibition in pituitary adenomas (33).

Not only coding genes have been related to EMT in pituitary tumors, some microRNAs (miRNAs) and long non-coding RNAs (lncRNAs) have been shown to modulate EMT. MiR149-5p and miR-99a-3p suppress the expression of EMT-related genes (34). miR-132, miR-15a and miR-16 also inhibit EMT in pituitary adenomas; in this case targeting SOX5 (35). Moreover, miR-424-3p inhibits EMT and invasion by targeting JAG1 (36). On the other hand, IncRNAs seem to be related to EMT enhancement rather than inhibition. For example, lncRNA SNHG6 induces EMT suppressing miR-944, which may inhibit RAB11A (37). Furthermore, lncRNA PVT1 enhances EMT and migration by activating $\mathrm{Wnt} / ß$-catenin (38). Finally, lncRNA SNHG1 promotes EMT and invasion by activation of TGFBR2/ $S M A D 3$ and $R A B 11 A / \mathrm{Wnt} / \beta$-Catenin axis, and the inhibition of miRNAs such as miR-302/372/373/520 (39).

EMT is a dynamic process, not a binary process, with intermediary states (2). It is very unlikely that benign tumor cells undergo a complete mesenchymal transformation which is associated with metastatic tumors (5). Because of that, it is more likely that, as in the majority of neoplasms, pituitary tumors would exhibit partial EMT states (40). This would explain why in transcriptomic analysis some EMT markers are up-regulated while others do not, instead of showing a complete mesenchymal profile $(9,41)$.

It is noteworthy to highlight the importance of the tumor microenvironment in mediating EMT and, therefore, the aggressive behavior of pituitary adenomas. The alteration of the tumor microenvironment seems to be triggered by tumor chemokines that attract immune cells (42). Additionally, IL-6 and CCL2 produced by tumor associated fibroblasts have been associated with EMT-like morphological changes and aggressive behavior trough E-cadherin downregulation and ZEB1 upregulation in an in vitro study (43).

It is really important to confirm the link between EMT and $A I P$, since AIP-ZAC1 pathway is one of the main molecular mechanisms described for SRLs resistance (44). SRLs can activate $A I P$ which inhibits adenylate cyclase, reducing cyclic AMP levels. On the other hand, AIP activates ZAC1. This molecule binds directly p53 and activates gene transcription; moreover, p53 arrests cell cycle, through p21 interaction, and increases apoptosis (45). Deeper explanation of the pathway could be found in some other reviews $(45,46)$.

\section{E-CADHERIN LOSS IS AN OUTSTANDING BIOMARKER FOR SRL RESISTANCE IN ACROMEGALY}

Somatostatin is secreted by the hypothalamus and inhibits hormone secretion and to a lesser extent pituitary cell growth by binding to different $\mathrm{G}$ protein-coupled receptors (SSTR1-5) [reviewed in Ben-Shlomo and Melmed (47)]. As remnant of its somatroph origin, somatotropinomas express somatostatin receptors, specially SSTR2 and SSTR5 (48). First-generation Somatostatin Receptor Ligands (SRLs), octreotide and lanreotide, so far the accepted first-line medical therapy in acromegaly despite that hormonal hypersecretion control of the disease is generally reported to be lower than $50 \%$ and both show a high affinity for SSTR2 receptor (49). Molecular characterization of the tumors has unveiled several explanations for such uneven response (50). However, many studies have proved the involvement of many other players and nowadays we do not know the whole picture of SRLs resistance in acromegaly.

EMT and epithelial plasticity have been associated with resistance to conventional, targeted and immune therapies in many cellular and preclinical models in different tumor contexts, although there is little evidence from clinical samples (51). In this line, different studies relate EMT and SRLs resistance in acromegaly. E-cadherin has been linked to SRLs response as an independent predictor by different studies and in different cohorts $(8,52,53)$. In a fair comparison between several known biomarkers of SRLs response, E-cadherin showed the greatest performance in predicting postsurgical SRLs response, even greater than SSTR2 or Ki-67 (8). There is a general consensus that low levels of E-cadherin mRNA and protein indicate a poor responsive tumor to SRLs $(8,52,53)$. Furthermore, E-cadherin loss seems to be related to the granulation pattern of the tumor, especially but not exclusively in $\mathrm{GH}$-producing tumors $(8,53)$. It is worth saying that the histological granulation pattern of the tumor has been related to SRLs response for many years $(54,55)$. Interestingly, some studies have shown the association between E-cadherin downregulation and E-cadherin promoter hypermethylation in $\mathrm{GH}$-secreting tumors, suggesting the involvement of epigenetic mechanisms (56-58). Another study pointed to the presence of progenitor mesenchymal cells derived from cancer stem cells as the cause of E-cadherin decrease and EMT induction (through TGFbRII increase) in somatotropinomas (59).

Taking into account that E-cadherin is routinely assessed in pathology departments as diagnostic tool for other cancer types (60), it would be easy to implement it as biomarker of response to SRLs to better define acromegaly treatment (61).

\section{BEYOND E-CADHERIN LOSS: INVOLVEMENT OF OTHER EPITHELIAL- MESENCHYMAL TRANSITION MOLECULES IN SRL RESISTANCE IN ACROMEGALY}

Since E-cadherin loss is a marker of advanced EMT, some authors have further investigated this phenomena in $\mathrm{GH}$ producing tumors. Lekva and colleagues analyzed the transcriptome of tumors with very high and very low levels of E-cadherin and identified several EMT-related genes. Interestingly, in vitro, the expression of these genes were not 
regulated by E-cadherin but by Epithelial Splicing Regulatory Protein1 (ESRP1) (6). ESRP1 has been characterized as an important contributor to EMT by mediating alternative splicing in EMT affecting the maintenance of epithelial features (62). It is important to mention that several studies have proved the relation of splicing and SRLs resistance in acromegaly $(7,63-$ 65). ESRP1, thus, may be a master regulator of the EMT, SRLs response and other pathological processes in acromegaly (7).

Lekva and colleagues also investigated genes that were differentially expressed upon treatment with SRLs in different EMT contexts. They found that RAR Related Orphan Receptor C $(R O R C)$ was overexpressed in phenotypically epithelial tumors but not in mesenchymal ones (9). Moreover, RORC expression was associated with SRLs response, a result that has been confirmed by finding that RORC is a biomarker of SRLs response improvement after surgical debulking (66).

On the other hand, patients harboring AIP-mutated somatotropinomas tend to be diagnosed at a younger age with larger, more aggressive, and SRLs resistance tumors (44). Some studies have shown that $A I P$ is an important mediator of SRLs response (45), and AIP expression has been found to be a potent SRLs response predictor (44). In this context, it was interesting to prove that the transcriptome of ten somatotropinomas and five normal pituitaries revealed EMT as one of the most significantly altered pathways in AIP-mutated tumors. Furthermore, the cellconditioned media of AIP-knockdown cells increases migration of macrophages (41), reinforcing the role of tumor microenvironment in inducing EMT and a more aggressive phenotype.

\section{CYTOSKELETON, EPITHELIAL- MESENCHYMAL TRANSITION, AND SRL RESISTANCE IN ACROMEGALY}

One of the main characteristics of EMT is the reorganization of cell polarity through changes in the cytoskeleton, which is composed of the actin cytoskeleton, the microtubule network and the intermediate filaments that provide structural design and mechanical strength. The cytoskeleton is known to play an important role in EMT during cancer progression (67). Concretely, refilin proteins perform their function through filamin A (FLNA) to regulate the actin cytoskeleton reorganization. RefilinA promotes the conversion of FLNA from an actin branching protein into an F-actin bundler, and RefilinB combined with FLNA organize a unique perinuclear actin network at the apical surface during the EMT $(68,69)$. Interestingly, in SNAI1-induced EMT, it has been proved that the changes in nuclear morphology and in the cytoskeleton structure correlate with decreased expression of FLNA (70).

FLNA plays an important role in GH-producing tumors since it has been related to pituitary tumors migration and invasion (71) and, more importantly, also to SRLs resistance (72). Additionally, it has been proved that FLNA mediates octreotide-induced SSTR2 trafficking through endosomal proteins in acromegaly. Moreover, FLNA influences the number of available SSTR2 at the surface of the cell (73).
For more detailed explanation of the cytoskeleton involvement in SRLs resistance, we recommend the review by Peverelli et al. published in 2015 in this same journal (74).

\section{EPITHELIAL-MESENCHYMAL TRANSITION-RELATED THERAPIES}

The involvement of EMT in acromegaly pathogenesis and SRLs resistance offers new therapeutic approaches that should be explored. As an example, CCNB1 overexpression in acromegaly can be targeted with resveratrol, inhibiting $C C N B 1$ and reverting its effects on invasion (31). Interestingly, Pasireotide, a second generation SRL, has been associated with a reduction of EMTassociated chemokines in tumor associated fibroblasts, suggesting an anti-tumor effect targeting the microenvironment (43). In contrast, other first generation SRLs do not appear to affect EMT (59).

Several EMT regulating TFs (SNAI1, SNAI2, TWIST...) can induce a therapy-resistant intrinsic mechanism (overexpression of drug efflux pumps) as well as an extrinsic one (gaining resistance to apoptosis inducing agents). This explains why EMT is often related to drug resistance in tumors (2). However, EMT features are emerging as novel therapeutic targets in cases of resistance to current therapies (75). Some of the drugs proposed to inhibit EMT in clinical phases are wellknown for endocrinologists such as metformin (76). Others have been proposed to be useful in acromegaly to target GDNF-RET/ PIT1/p14ARF/p53 pathway, like Sorafenib (77).

EMT offers target opportunities in different levels: inhibiting stimuli from the tumor microenvironment, inhibiting extracellular mediators and their corresponding receptors, inhibiting or activating intracellular signaling pathways, and inhibiting transcription factors that indirectly induce EMT (78). On this last regard, the usage of an inhibitor of STAT3 could very much benefit acromegaly therapy since it would act reverting EMT process (7981) and directly inhibiting GH hypersecretion (82). More than a dozen of different therapies targeting EMT are being tested in clinical trials, however the vast majority are used in combination with regular chemotherapy since it is expected to recover sensitivity of more conventional drugs upon EMT inhibition (78). In acromegaly, the main concern rather than the proliferation and formation of metastasis is the normalization of hormone levels; this is the reason why rather than the expected antiproliferative effects of these drugs, we would expect a resensitization to SRLs. However, nowadays it is unknown if this effect would be achieved and which molecules should be targeted.

\section{DISCUSSION}

It is very likely that EMT plays an important role in acromegaly pathogenesis, but also in the modulation of pharmacologic response, thus inducing SRLs resistance in particular. However, most of this relationship is unknown since the molecular pathways relating EMT and SRLs signaling are not really understood and sufficiently explored. We are only beginning to 
unveil this relationship and we have, by now, been able to find some of the key molecules, but the whole picture remains elusive. To add a little more complexity to the acromegaly and EMT relationship, it is worth to mention that one of the surprising effects of GH is the induction of EMT (83), closing the circle around EMT and acromegaly. The induction of EMT by GH seems to be mediated by the tumor microenvironment involving not only tumor cells but multiple non-tumoral cell types $(84,85)$.

Importantly, the study of EMT has provided some interesting biomarkers to predict SRLs response in acromegaly, for example, E-cadherin and RORC. Furthermore, as we could only glimpse for now, EMT in acromegaly is involved in a lot of processes like stemness, apoptosis, secretory vesicles trafficking, cytoskeleton organization, invasion capacities and aberrant splicing. All of them are, to some extent, individually related to SRLs resistance and that makes very difficult to delimitate the action of EMT. It forces to contemplate EMT as a dynamic process with deep connections with a multitude of different cellular programs. Moreover, the presence of intermediate EMT states in tumors, which generates tumor heterogeneity, is probably key in the contribution of EMT to treatment resistance.

Further studies of the EMT process would not only provide in-deep knowledge about the dedifferentiation of GH-secreting tumors and the SRLs desensitization, but will certainly offer alternative treatments to the SRLs. Several EMT inhibitors are currently been tested in clinical trials for other malignancies. The plastic and dynamic nature of EMT increases the difficulty in determining the appropriate therapeutic and diagnostic windows. However, targeting EMT blockade as an adjuvant therapy could potentially increase the effectiveness of the GHsecreting tumors to SRLs.

\section{REFERENCES}

1. Yang J, Antin P, Berx G, Blanpain C, Brabletz T, Bronner M, et al. Guidelines and definitions for research on epithelial-mesenchymal transition. Nat Rev Mol Cell Biol (2020) 6. doi: 10.1038/s41580-020-0237-9

2. Nieto MA, Huang RY-J, Jackson RA, Thiery JP. EMT: 2016. Cell (2016) 166:21-45. doi: 10.1016/j.cell.2016.06.028

3. Pastushenko I, Blanpain C. EMT Transition States during Tumor Progression and Metastasis. Trends Cell Biol (2019) 29:212-26. doi: 10.1016/ j.tcb.2018.12.001

4. Stemmler MP, Eccles RL, Brabletz S, Brabletz T. Non-redundant functions of EMT transcription factors. Nat Cell Biol (2019) 21:102-12. doi: 10.1038/ s41556-018-0196-y

5. Brabletz T, Kalluri R, Nieto MA, Weinberg RA. EMT in cancer. Nat Rev Cancer (2018) 18:128-34. doi: 10.1038/nrc.2017.118

6. Lekva T, Berg JP, Fougner SL, Olstad OK, Ueland T, Bollerslev J. Gene expression profiling identifies ESRP1 as a potential regulator of epithelial mesenchymal transition in somatotroph adenomas from a large cohort of patients with acromegaly. J Clin Endocrinol Metab (2012) 97:E1506-14. doi: 10.1210/jc.2012-1760

7. Lekva T, Berg JP, Lyle R, Heck A, Ringstad G, Olstad OK, et al. Epithelial Splicing Regulator Protein 1 and Alternative Splicing in Somatotroph Adenomas. Endocrinology (2013) 154:3331-43. doi: 10.1210/en.2013-1051

8. Puig-Domingo M, Gil J, Sampedro Nuñez M, Jordà M, Webb SM, Serra G, et al. Molecular profiling for acromegaly treatment: a validation study. Endocr Relat Cancer (2020) 27. doi: 10.1530/ERC-18-0565

9. Lekva T, Berg JP, Heck A, Lyngvi Fougner S, Olstad OK, Ringstad G, et al. Attenuated RORC expression in the presence of EMT progression in
In conclusion, EMT is a process that plays an important role in the heterogeneity of pituitary adenomas and is associated with a more aggressive phenotype. Furthermore, it has been linked to SRLs response in somatotropinomas. Thus, EMT-related therapies may be taken into consideration in the treatment of acromegaly, especially in SRLs non-responder patients. This could be an opportunity to find new therapies for pituitary adenomas; however, the increasing therapeutic options for acromegaly may overwhelm clinicians making more difficult the choice of the best molecule(s) to target. In this regard, some authors have developed a universal and quantitative EMT scoring based on transcriptomic data that allows the prediction of response to different pharmacological treatments (86). We think that this type of tools should be the basis of the future medicine in acromegaly; the "trial-and-error" approach to decide the appropriate drug would no longer be an option (87-90).

\section{AUTHOR CONTRIBUTIONS}

All authors listed have made a substantial, direct, and intellectual contribution to the work and approved it for publication.

\section{FUNDING}

Work in our laboratory is supported by the Instituto de salud Carlos III (PM 15/00027) and Novartis through the REMAH (Registro Español Molecular de Adenomas Hipofisarios) consortium to the SEEN (Sociedad Española de Endocrinología y Nutrición). somatotroph adenomas following treatment with somatostatin analogs is associated with poor clinical recovery. PloS One (2013) 8:e66927. doi: 10.1371/journal.pone.0066927

10. de Moraes DC, Vaisman M, Conceição FL, Ortiga-Carvalho TM. Pituitary development: a complex, temporal regulated process dependent on specific transcriptional factors. J Endocrinol (2012) 215:239-45. doi: 10.1530/JOE12-0229

11. Dubois PM, ElAmraoui A. Embryology of the pituitary gland. Trends Endocrinol Metab (1995) 6:1-7. doi: 10.1016/1043-2760(94)00090-Q

12. Pérez Millán MI, Brinkmeier ML, Mortensen AH, Camper SA. PROP1 triggers epithelial-mesenchymal transition-like process in pituitary stem cells. Elife (2016) 5. doi: 10.7554/eLife.14470

13. Cheung LYM, Davis SW, Brinkmeier ML, Camper SA, Pérez-Millán MI. Regulation of pituitary stem cells by epithelial to mesenchymal transition events and signaling pathways. Mol Cell Endocrinol (2017) 445:14-26. doi: 10.1016/j.mce.2016.09.016

14. Zhang S, Cui Y, Ma X, Yong J, Yan L, Yang M, et al. Single-cell transcriptomics identifies divergent developmental lineage trajectories during human pituitary development. Nat Commun (2020) 11:5275. doi: 10.1038/s41467-020-19012-4

15. Kusumoto K, Kikuchi M, Fujiwara K, Horiguchi K, Kouki T, Kawanishi K, et al. Effect of E-cadherin Expression on Hormone Production in Rat Anterior Pituitary Lactotrophs In Vitro. Acta Histochem Cytochem (2010) 43:83-8. doi: 10.1267/ahc.10001

16. Kolnes AJ, Øystese KAB, Olarescu NC, Ringstad G, Berg-Johnsen J, CasarBorota O, et al. FSH Levels Are Related to E-cadherin Expression and Subcellular Location in Nonfunctioning Pituitary Tumors. J Clin Endocrinol Metab (2020) 105:2587-94. doi: 10.1210/clinem/dgaa281 
17. Mège RM, Ishiyama N. Integration of Cadherin Adhesion and Cytoskeleton at Adherens Junctions. Cold Spring Harb Perspect Biol (2017) 9. doi: 10.1101/ cshperspect.a028738

18. Du W, Liu X, Fan G, Zhao X, Sun Y, Wang T, et al. From cell membrane to the nucleus: an emerging role of E-cadherin in gene transcriptional regulation. J Cell Mol Med (2014) 18:1712-9. doi: 10.1111/jcmm.12340

19. Elston MS, Gill AJ, Conaglen JV, Clarkson A, Cook RJ, Little NS, et al. Nuclear accumulation of e-cadherin correlates with loss of cytoplasmic membrane staining and invasion in pituitary adenomas. J Clin Endocrinol Metab (2009) 94:1436-42. doi: 10.1210/jc.2008-2075

20. Qian ZR, Li CC, Yamasaki H, Mizusawa N, Yoshimoto K, Yamada S, et al. Role of E-Cadherin, $\alpha-, \beta-$, and $\gamma$-Catenins, and p120 (Cell Adhesion Molecules) in Prolactinoma Behavior. Mod Pathol (2002) 15:1357-65. doi: 10.1097/01.MP.0000039572.75188.1A

21. Chauvet N, Romanò N, Meunier A-C, Galibert E, Fontanaud P, Mathieu M$\mathrm{N}$, et al. Combining Cadherin Expression with Molecular Markers Discriminates Invasiveness in Growth Hormone and Prolactin Pituitary Adenomas. J Neuroendocrinol (2016) 28. doi: 10.1111/jne.12352

22. Jia W, Zhu J, Martin TA, Jiang A, Sanders AJ, Jiang WG. Epithelialmesenchymal Transition (EMT) Markers in Human Pituitary Adenomas Indicate a Clinical Course. Anticancer Res (2015) 35:2635-43.

23. Zhou K, Jin H, Luo Y. Expression and Significance of E-Cadherin and $\beta$ Catenins in Pituitary Adenoma. Int J Surg Pathol (2013) 21:363-7. doi: $10.1177 / 1066896912471850$

24. Mendes GA, Haag T, Trott G, Rech CGSL, Ferreira NP, Oliveira MC, et al. Expression of E-cadherin, Slug and NCAM and its relationship to tumor invasiveness in patients with acromegaly. Braz J Med Biol Res (2018) 51. doi: 10.1590/1414-431x20176808

25. Wang J, Zhang Z, Li R, Mao F, Sun W, Chen J, et al. ADAM12 induces EMT and promotes cell migration, invasion and proliferation in pituitary adenomas via EGFR/ERK signaling pathway. BioMed Pharmacother (2018) 97:1066-77. doi: 10.1016/j.biopha.2017.11.034

26. Falch CM, Sundaram AYM, Øystese KA, Normann KR, Lekva T, Silamikelis I, et al. Gene expression profiling of fast- and slow-growing non-functioning gonadotroph pituitary adenomas. Eur J Endocrinol (2018) 178:295-307. doi: 10.1530/EJE-17-0702

27. Wang H, Chen K, Yang Z, Li W, Wang C, Zhang G, et al. Diagnosis of Invasive Nonfunctional Pituitary Adenomas by Serum Extracellular Vesicles. Anal Chem (2019) 91:9580-9. doi: 10.1021/acs.analchem.9b00914

28. Méndez-Vidal C, Gámez-Del Estal M del M, Moreno-Mateos MA, EspinaZambrano ÁG, Torres B, Pintor-Toro JA. PTTG2 silencing results in induction of epithelial-to-mesenchymal transition and apoptosis. Cell Death Dis (2013) 4:e530-0. doi: 10.1038/cddis.2013.48

29. Huang N, Zhao G, Yang Q, Tan J, Tan Y, Zhang J, et al. Intracellular and extracellular S100A9 trigger epithelial-mesenchymal transition and promote the invasive phenotype of pituitary adenoma through activation of AKT1. Aging (Albany NY) (2020) 12. doi: 10.18632/aging.104072

30. Neou M, Villa C, Armignacco R, Jouinot A, Raffin-Sanson M-L, Septier A, et al. Pangenomic Classification of Pituitary Neuroendocrine Tumors. Cancer Cell (2020) 37:123-34. doi: 10.1016/j.ccell.2019.11.002

31. Li B, Zhu H, Song G, Cheng J, Li C, Zhang Y, et al. Regulating the CCNB1 gene can affect cell proliferation and apoptosis in pituitary adenomas and activate epithelial-to-mesenchymal transition. Oncol Lett (2019) 18. doi: 10.3892/ ol.2019.10847

32. Shan X, Liu Q, Li Z, Li C, Gao H, Zhang Y. Epithelial-Mesenchymal Transition Induced by SMAD4 Activation in Invasive Growth Hormone-Secreting Adenomas. Open Chem (2018) 16:571-82. doi: 10.1515/chem-2018-0061

33. Long R, Liu Z, Li J, Yu H. COL6A6 interacted with P4HA3 to suppress the growth and metastasis of pituitary adenoma via blocking PI3K-Akt pathway. Aging (Albany NY) (2019) 11:8845-59. doi: 10.18632/aging.102300

34. Zhao P, Cheng J, Li B, Nie D, Li C, Gui S, et al. Up-regulation of the expressions of MiR-149-5p and MiR-99a-3p in exosome inhibits the progress of pituitary adenomas. Cell Biol Toxicol (2021) 1. doi: 10.1007/s10565-020-09570-0

35. Renjie W, Haiqian L. MiR-132, miR-15a and miR-16 synergistically inhibit pituitary tumor cell proliferation, invasion and migration by targeting Sox5. Cancer Lett (2015) 356:568-78. doi: 10.1016/j.canlet.2014.10.003

36. Chen Y, Li B, Feng J, Fang Q, Cheng J, Xie W, et al. JAG1, Regulated by microRNA-424-3p, Involved in Tumorigenesis and Epithelial-Mesenchymal
Transition of High Proliferative Potential-Pituitary Adenomas. Front Onco (2020) 10:2785-98. doi: 10.3389/fonc.2020.567021

37. Mao D, Jie Y, Lv Y. LncRNA SNHG6 Induces Epithelial-Mesenchymal Transition of Pituitary Adenoma Via Suppressing MiR-944. Cancer Biother Radiopharm (2020). doi: 10.1089/cbr.2020.3587

38. Zhang $\mathrm{Y}$, Tan $\mathrm{Y}$, Wang $\mathrm{H}, \mathrm{Xu} \mathrm{M}, \mathrm{Xu}$ L. Long Non-Coding RNA Plasmacytoma Variant Translocation 1 (PVT1) Enhances Proliferation, Migration, and Epithelial-Mesenchymal Transition (EMT) of Pituitary Adenoma Cells by Activating $\beta$-Catenin, c-Myc, and Cyclin D1 Expression. Med Sci Monit (2019) 25:7652-9. doi: 10.12659/MSM.917110

39. Wang H, Wang G, Gao Y, Zhao C, Li X, Zhang F, et al. Lnc-SNHG1 Activates the TGFBR2/SMAD3 and RAB11A/Wnt/ $\beta$-Catenin Pathway by Sponging MiR-302/372/373/520 in Invasive Pituitary Tumors. Cell Physiol Biochem (2018) 48:1291-303. doi: 10.1159/000492089

40. Grigore A, Jolly M, Jia D, Farach-Carson M, Levine H. Tumor Budding: The Name is EMT. Partial EMT. J Clin Med (2016) 5:51. doi: 10.3390/jcm5050051

41. Barry S, Carlsen E, Marques P, Stiles CE, Gadaleta E, Berney DM, et al. Tumor microenvironment defines the invasive phenotype of AIP-mutation-positive pituitary tumors. Oncogene (2019) 38:5381-95. doi: 10.1038/s41388-019-0779-5

42. Marques P, Barry S, Carlsen E, Collier D, Ronaldson A, Awad S, et al. Chemokines modulate the tumour microenvironment in pituitary neuroendocrine tumours. Acta Neuropathol Commun (2019) 7:172. doi: 10.1186/s40478-019-0830-3

43. Marques P, Barry S, Carlsen E, Collier D, Ronaldson A, Awad S, et al. Pituitary tumour fibroblast-derived cytokines influence tumour aggressiveness. Endocr Relat Cancer (2019) 26:853-65. doi: 10.1530/ERC-19-0327

44. Chahal HS, Trivellin G, Leontiou CA, Alband N, Fowkes RC, Tahir A, et al. Somatostatin analogs modulate AIP in somatotroph adenomas: the role of the ZAC1 pathway. J Clin Endocrinol Metab (2012) 97:E1411-20. doi: 10.1210/ jc.2012-1111

45. Ibáñez-Costa A, Korbonits M. AIP and the somatostatin system in pituitary tumours. J Endocrinol (2017) 235:R101-16. doi: 10.1530/JOE-17-0254

46. Gadelha MR, Wildemberg LE, Bronstein MD, Gatto F, Ferone D. Somatostatin receptor ligands in the treatment of acromegaly. Pituitary (2017) 20:100-8. doi: 10.1007/s11102-017-0791-0

47. Ben-Shlomo A, Melmed S. Pituitary somatostatin receptor signaling. Trends Endocrinol Metab (2010) 21:123-33. doi: 10.1016/j.tem.2009.12.003

48. Taboada GF, Luque RM, Neto LV, Machado E de O, Sbaffi BC, Domingues $\mathrm{RC}$, et al. Quantitative analysis of somatostatin receptor subtypes (1-5) gene expression levels in somatotropinomas and correlation to in vivo hormonal and tumor volume responses to treatment with octreotide LAR. Eur J Endocrinol (2008) 158:295-303. doi: 10.1530/EJE-07-0562

49. Colao A, Auriemma RS, Lombardi G, Pivonello R. Resistance to Somatostatin Analogs in Acromegaly. Endocr Rev (2011) 32:247-71. doi: 10.1210/er.2010-0002

50. Gadelha MR, Kasuki L, Korbonits M. Novel pathway for somatostatin analogs in patients with acromegaly. Trends Endocrinol Metab (2013) 24:238-46. doi: $10.1016 /$ j.tem.2012.11.007

51. Santamaría PG, Moreno-Bueno G, Cano A. Contribution of Epithelial Plasticity to Therapy Resistance. J Clin Med (2019) 8:676. doi: 10.3390/ jcm8050676

52. Fougner SL, Lekva T, Borota OC, Hald JK, Bollerslev J, Berg JP. The expression of E-cadherin in somatotroph pituitary adenomas is related to tumor size, invasiveness, and somatostatin analog response. J Clin Endocrinol Metab (2010) 95:2334-42. doi: 10.1210/jc.2009-2197

53. Venegas-Moreno E, Flores-Martinez A, Dios E, Vazquez-Borrego MC, Ibañez-Costa A, Madrazo-Atutxa A, et al. E-cadherin expression is associated with somatostatin analogue response in acromegaly. $\mathrm{J}$ Cell $\mathrm{Mol}$ Med (2019) 23:3088-96. doi: 10.1111/jcmm.13851

54. Fougner SL, Casar-Borota O, Heck A, Berg JP, Bollerslev J. Adenoma granulation pattern correlates with clinical variables and effect of somatostatin analogue treatment in a large series of patients with acromegaly. Clin Endocrinol (Oxf) (2012) 76:96-102. doi: 10.1111/j.1365-2265.2011.04163.x

55. Kiseljak-Vassiliades K, Carlson NE, Borges MT, Kleinschmidt-DeMasters BK, Lillehei KO, Kerr JM, et al. Growth hormone tumor histological subtypes predict response to surgical and medical therapy. Endocrine (2015) 49:231-41. doi: 10.1007/s12020-014-0383-y

56. Qian ZR, Sano T, Yoshimoto K, Asa SL, Yamada S, Mizusawa N, et al. Tumorspecific downregulation and methylation of the CDH13 (H-cadherin) and 
CDH1 (E-cadherin) genes correlate with aggressiveness of human pituitary adenomas. Mod Pathol (2007) 20:1269-77. doi: 10.1038/modpathol.3800965

57. Sano T, Rong QZ, Kagawa N, Yamada S. Down-Regulation of E-Cadherin and Catenins in Human Pituitary Growth Hormone-Producing Adenomas. In: Molecular Pathology of the Pituitary. Basel: KARGER. (2004) p. 127-32. doi: 10.1159/000079041

58. Xu B, Sano T, Yoshimoto K, Yamada S. Downregulation of E-Cadherin and Its Undercoat Proteins in Pituitary Growth Hormone Cell Adenomas with Prominent Fibrous Bodies. Endocr Pathol (2002) 13:341-52. doi: 10.1385/ EP:13:4:341

59. Orciani M, Caffarini M, Sorgentoni G, Ricciuti RA, Arnaldi G, Di Primio R. Effects of somatostatin and its analogues on progenitor mesenchymal cells isolated from human pituitary adenomas. Pituitary (2017) 20:251-60. doi: 10.1007/s11102-016-0770-x

60. Pai K, Baliga P. Shrestha BL. E-cadherin expression: a diagnostic utility for differentiating breast carcinomas with ductal and lobular morphologies. J Clin Diagn Res (2013) 7:840-4. doi: 10.7860/JCDR/2013/5755.2954

61. Mete O, Asa SL. Structure, Function, and Morphology in the Classification of Pituitary Neuroendocrine Tumors: the Importance of Routine Analysis of Pituitary Transcription Factors. Endocr Pathol (2020) 4. doi: 10.1007/s12022020-09646-x

62. Warzecha CC, Jiang P, Amirikian K, Dittmar KA, Lu H, Shen S, et al. An ESRP-regulated splicing programme is abrogated during the epithelialmesenchymal transition. EMBO J (2010) 29:3286-300. doi: 10.1038/ emboj.2010.195

63. Luque RM, Ibáñez-Costa A, Neto LV, Taboada GF, Hormaechea-Agulla D, Kasuki L, et al. Truncated somatostatin receptor variant sst5TMD4 confers aggressive features (proliferation, invasion and reduced octreotide response) to somatotropinomas. Cancer Lett (2015) 359:299-306. doi: 10.1016/ j.canlet.2015.01.037

64. Ibáñez-Costa A, Gahete MD, Rivero-Cortés E, Rincón-Fernández D, Nelson $\mathrm{R}$, Beltrán M, et al. In1-ghrelin splicing variant is overexpressed in pituitary adenomas and increases their aggressive features. Sci Rep (2015) 5:8714. doi: $10.1038 /$ srep08714

65. Lekva T, Berg JP, Lyle R, Heck A, Bollerslev J, Ueland T. Alternative splicing of placental lactogen $(\mathrm{CSH} 2)$ in somatotroph pituitary adenomas. Neuro Endocrinol Lett (2015) 36:136-42.

66. Gil J, Marqués-Pamies M, Jordà M, Fajardo-Montañana C, García-Martínez A, Sampedro M, et al. Molecular determinants of enhanced response to somatostatin receptor ligands after debulking in large GH producing adenomas. Clin Endocrinol (Oxf) (2020). doi: 10.1111/cen.14339

67. Sun B, Fang Y, Li Z, Chen Z, Xiang J. Role of cellular cytoskeleton in epithelialmesenchymal transition process during cancer progression. BioMed Rep (2015) 3:603-10. doi: 10.3892/br.2015.494

68. Gay O, Gilquin B, Nakamura F, Jenkins ZA, McCartney R, Krakow D, et al. RefilinB (FAM101B) targets FilaminA to organize perinuclear actin networks and regulates nuclear shape. Proc Natl Acad Sci (2011) 108:11464-9. doi: 10.1073/pnas.1104211108

69. Gay O, Gilquin B, Pitaval A, Baudier J. Refilins. Bioarchitecture (2011) 1:2459. doi: $10.4161 /$ bioa. 18246

70. McGrail DJ, Mezencev R, Kieu QMN, McDonald JF, Dawson MR. SNAILinduced epithelial-to-mesenchymal transition produces concerted biophysical changes from altered cytoskeletal gene expression. FASEB J (2015) 29:1280-9. doi: 10.1096/fj.14-257345

71. Mantovani G, Treppiedi D, Giardino E, Catalano R, Mangili F, Vercesi P, et al. Cytoskeleton actin-binding proteins in clinical behavior of pituitary tumors. Endocr Relat Cancer (2019) 26:R95-108. doi: 10.1530/ERC-18-0442

72. Coelho MCA, Vasquez ML, Wildemberg LE, Vázquez-Borrego MC, Bitana L, Camacho AH da S, et al. Clinical significance of filamin A in patients with acromegaly and its association with somatostatin and dopamine receptor profiles. Sci Rep (2019) 9:1122. doi: 10.1038/s41598-018-37692-3

73. Treppiedi D, Mangili F, Giardino E, Catalano R, Locatelli M, Lania AG, et al. Cytoskeleton Protein Filamin A Is Required for Efficient Somatostatin Receptor Type 2 Internalization and Recycling through Rab5 and Rab4 Sorting Endosomes in Tumor Somatotroph Cells. Neuroendocrinology (2020) 110:642-52. doi: 10.1159/000503791

74. Peverelli E, Treppiedi D, Giardino E, Vitali E, Lania AG, Mantovani G. Dopamine and Somatostatin Analogues Resistance of Pituitary Tumors:
Focus on Cytoskeleton Involvement. Front Endocrinol (Lausanne) (2015) 6:187-97. doi: 10.3389/fendo.2015.00187

75. Singh M, Yelle N, Venugopal C, Singh SK. EMT: Mechanisms and therapeutic implications. Pharmacol Ther (2018) 182:80-94. doi: 10.1016/j.pharmthera. 2017.08.009

76. Kordes S, Pollak MN, Zwinderman AH, Mathôt RA, Weterman MJ, Beeker A, et al. Metformin in patients with advanced pancreatic cancer: a double-blind, randomised, placebo-controlled phase 2 trial. Lancet Oncol (2015) 16:839-47. doi: 10.1016/S1470-2045(15)00027-3

77. Chenlo M, Rodriguez-Gomez IA, Serramito R, Garcia-Rendueles AR, Villar-Taibo R, Fernandez-Rodriguez E, et al. Unmasking a new prognostic marker and therapeutic target from the GDNF-RET/PIT1/p14ARF/p53 pathway in acromegaly. EBioMedicine (2019) 43:537-52. doi: 10.1016/ j.ebiom.2019.04.007

78. Marcucci F, Stassi G, De Maria R. Epithelial-mesenchymal transition: a new target in anticancer drug discovery. Nat Rev Drug Discovery (2016) 15:311-25. doi: 10.1038/nrd.2015.13

79. Yue P, Zhang X, Paladino D, Sengupta B, Ahmad S, Holloway RW, et al. Hyperactive EGF receptor, Jaks and Stat3 signaling promote enhanced colony-forming ability, motility and migration of cisplatin-resistant ovarian cancer cells. Oncogene (2012) 31:2309-22. doi: 10.1038/onc.2011.409

80. Colomiere M, Ward AC, Riley C, Trenerry MK, Cameron-Smith D, Findlay J, et al. Cross talk of signals between EGFR and IL-6R through JAK2/STAT3 mediate epithelial-mesenchymal transition in ovarian carcinomas. $\mathrm{Br} \mathrm{J}$ Cancer (2009) 100:134-44. doi: 10.1038/sj.bjc.6604794

81. Ashizawa T, Akiyama Y, Miyata H, Iizuka A, Komiyama M, Kume A, et al. Effect of the STAT3 inhibitor STX-0119 on the proliferation of a temozolomide-resistant glioblastoma cell line. Int J Oncol (2014) 45:411-8. doi: $10.3892 /$ ijo.2014.2439

82. Zhou C, Jiao Y, Wang R, Ren S-G, Wawrowsky K, Melmed S. STAT3 upregulation in pituitary somatotroph adenomas induces growth hormone hypersecretion. J Clin Invest (2015) 125:1692-702. doi: 10.1172/JCI78173

83. Brittain AL, Basu R, Qian Y, Kopchick JJ. Growth Hormone and the Epithelial-to-Mesenchymal Transition. J Clin Endocrinol Metab (2017) 102:3662-73. doi: 10.1210/jc.2017-01000

84. Chesnokova V, Melmed S. Growth hormone in the tumor microenvironment. Arch Endocrinol Metab (2020) 63:568-75. doi: 10.20945/2359-3997000000186

85. Chesnokova V, Zonis S, Zhou C, Recouvreux MV, Ben-Shlomo A, Araki T, et al. Growth hormone is permissive for neoplastic colon growth. Proc Natl Acad Sci U.S.A. (2016) 113:E3250-9. doi: 10.1073/pnas.1600561113

86. Tan TZ, Miow QH, Miki Y, Noda T, Mori S, Huang RY, et al. Epithelialmesenchymal transition spectrum quantification and its efficacy in deciphering survival and drug responses of cancer patients. EMBO Mol Med (2014) 6:1279-93. doi: 10.15252/emmm.201404208

87. Lesko LJ. Personalized Medicine: Elusive Dream or Imminent Reality? Clin Pharmacol Ther (2007) 81:807-16. doi: 10.1038/sj.clpt.6100204

88. Kasuki L, Wildemberg LE, Gadelha MR. MANAGEMENT OF ENDOCRINE DISEASE: Personalized medicine in the treatment of acromegaly. Eur $J$ Endocrinol (2018) 178:R89-R100. doi: 10.1530/EJE-17-1006

89. Puig Domingo M. Treatment of acromegaly in the era of personalized and predictive medicine. Clin Endocrinol (Oxf) (2015) 83:3-14. doi: 10.1111/cen.12731

90. Gadelha MR. A paradigm shift in the medical treatment of acromegaly: from a "trial and error" to a personalized therapeutic decision-making process. Clin Endocrinol (Oxf) (2015) 83:1-2. doi: 10.1111/cen.12797

Conflict of Interest: MP-D declares to have received funding from Novartis through the REMAH consortium for research purposes.

The remaining authors declare that the research was conducted in the absence of any commercial or financial relationships that could be construed as a potential conflict of interest.

Copyright (c) 2021 Gil, Jordà, Soldevila and Puig-Domingo. This is an open-access article distributed under the terms of the Creative Commons Attribution License (CC BY). The use, distribution or reproduction in other forums is permitted, provided the original author(s) and the copyright owner(s) are credited and that the original publication in this journal is cited, in accordance with accepted academic practice. No use, distribution or reproduction is permitted which does not comply with these terms. 